\title{
Malaria distribution and performance of malaria diagnostic methods in Malaysia (1980-2019): a systematic review
}

\author{
Mohd Amirul Fitri A. Rahim, Mohd Bakhtiar Munajat and Zulkarnain Md Idris ${ }^{*}$ []
}

\begin{abstract}
Background: Malaysia has already achieved remarkable accomplishments in reaching zero indigenous human malaria cases in 2018. Prompt malaria diagnosis, surveillance and treatment played a key role in the country's elimination success. Looking at the dynamics of malaria distribution during the last decades might provide important information regarding the potential challenges of such an elimination strategy. This study was performed to gather all data available in term of prevalence or incidence on Plasmodium infections in Malaysia over the last four decades.
\end{abstract}

Methods: A systematic review of the published English literature was conducted to identify malaria distribution from 1980 to June 2019 in Malaysia. Two investigators independently extracted data from PubMed, Scopus, Web of Science and Elsevier databases for original papers.

Results: The review identified 46 epidemiological studies in Malaysia over the 39-year study period, on which sufficient information was available. The majority of studies were conducted in Malaysia Borneo $(31 / 46 ; 67.4 \%)$, followed by Peninsular Malaysia $(13 / 46 ; 28.3 \%)$ and in both areas $(2 / 46 ; 4.3 \%)$. More than half of all studies $(28 / 46 ; 60.9 \%)$ were assessed by both microscopy and PCR. Furthermore, there was a clear trend of decreases of all human malaria species with increasing Plasmodium knowlesi incidence rate throughout the year of sampling period. The summary estimates of sensitivity were higher for P. knowlesi than other Plasmodium species for both microscopy and PCR. Nevertheless, the specificities of summary estimates were similar for microscopy (40-43\%), but varied for PCR (2-34\%).

Conclusions: This study outlined the epidemiological changes in Plasmodium species distribution in Malaysia. Malaria cases shifted from predominantly caused by human malaria parasites to simian malaria parasites, which accounted for the majority of indigenous cases particularly in Malaysia Borneo. Therefore, malaria case notification and prompt malaria diagnosis in regions where health services are limited in Malaysia should be strengthened and reinforced to achieving the final goal of malaria elimination in the country.

Keyword: Malaria, Malaysia, Distribution, Diagnostic, Systematic review

\section{Background}

Malaria is one of the most prevalent mosquito-borne infectious diseases in the world. An approximately 228 million malaria cases and 405,000 deaths were reported

*Correspondence: zulkarnain.mdidris@ukm.edu.my

Department of Parasitology and Medical Entomology, Faculty

of Medicine, Universiti Kebangsaan Malaysia, 56000 Kuala Lumpur,

Malaysia in 2019 globally [1]. Although an estimated 20 million fewer cases were reported in 2019 than in the previous ten years, no significant progress has been made in reducing global malaria cases over this timeframe $[1,2]$. The majority of cases in 2019 were in the World Health Organization (WHO) African Region (213 million or 93\%), followed by $3.4 \%$ from the WHO South-East Asia Region and the WHO Eastern Mediterranean Region accounted for $2.1 \%$ of the overall cases [1]. Of all five 
species of malaria that infect human i.e. Plasmodium falciparum, Plasmodium vivax, Plasmodium malariae, Plasmodium ovale and Plasmodium knowlesi. Plasmodium falciparum is the most prevalent and causes the highest mortality particularly in the African region [3].

In the WHO Western Pacific Region, there are 753 million people in 10 countries that are currently at risk of infections with malaria [1]. Malaysia, which is included in this region, is in the pre-elimination phase and continues to progress towards elimination, reporting zero indigenous human malaria cases in 2018 [3], which is two years ahead of target elimination in 2020 [4]. This is particularly impressive considering that in 2010, over 5000 cases were reported in the country [3]. Even though malaria control activities have significantly reduced human malaria incidence in Malaysia, the resurgence of the malaria parasite $P$. knowlesi still remains as a main public health problem in the less developed areas of the country, especially in Malaysia Borneo [5-7] and among hardto-reach populations of indigenous people in Peninsular Malaysia [8-11]. About one-third (32\%) of total malaria cases occur in Peninsular Malaysia, and the majority of these are found in the central, south-eastern and northern coastal regions [6]. The remaining 68 percent of cases are found in Malaysian Borneo, primarily the states of Sabah and Sarawak [5]. Previous studies revealed that higher historical forest loss could be one of the factors that were significantly associated with higher incidence of $P$. knowlesi infection in Malaysia [12-16].

Currently, several types of malaria diagnostic methods are available including light microscopy, rapid diagnostic tests (RDTs) and polymerase chain reaction (PCR) assay. In Malaysia, light microscopy examination of blood slides is the primary method in malaria diagnosis $[17,18]$. This method remains the gold standard for malaria diagnosis and has clear advantages; it is inexpensive and allows for identification and quantification of malaria species [19, $20]$. However, the quality of a diagnosis based on microscopy is often inadequate. The accuracy depends on the level of competence of the microscopist and may be adversely affected by operational limitations or technical problems [19, 21, 22]. Plus, infections with low density are unlikely to be detected by conventional microscopy [23-25]. Unlike microscopy, malaria RDTs requiring no technical equipment and minimal expertise [26]. However, RDTs do not provide parasite quantification and are considered more expensive than light microscopy [19]. Molecular techniques such as PCR are more accurate in identification and differentiation of all malaria species than microscopy and RDT [10, 27-29]. Despite the greater sensitivity of PCR, it is not convenient for field and resource-limited settings due to the requirement of complex equipment, reagents and know-how [19]. The
Malaysia government has adopted various strategies to eliminate malaria including access to early diagnosis and treatment, a strong surveillance system and effective vector control measures [17].

Several studies have been conducted to assess prevalence of Plasmodium spp. in Malaysia. However, there is no detailed systematic review on malaria epidemiology and information on changes in prevalence or incidence over the past decades. Therefore, the aim of this study was to collate relevant published studies related to the distribution of malaria in Malaysia through a systematic review strategy from 1980 to 2019.

\section{Methods}

\section{Search strategy}

This systematic review was conducted using published studies on the prevalence of malaria in Malaysia. Eligible studies were identified in PubMed, Scopus, Web of Science (Clarivate Analytic) and Elsevier (Science Direct) databases searched from January 1980 to June 2019. The search was commonly conducted using the search term [("Plasmodium" OR "malaria") AND ("prevalence" OR "epidemiology") AND "Malaysia"] of combination to obtain relevant articles. This systematic review was accorded to the protocol and followed the PRISMA (Preferred Reporting Items for Systematic Reviews and Metaanalysis) guidelines [30].

\section{Eligibility criteria}

Primary malaria research conducted in Malaysia was included in this study including the previous reports of prevalence or incidence of malaria in the country. Only full-text articles in English were considered. The articles must also provide a description of sample size, study design, study site, malaria diagnosis method as well as duration of study. For exclusion criteria, this study excluded previous articles on case reports, letters, posters, conference abstracts, and studies conducted through experimental works of malaria in animal models. Articles with insufficient data, and literature reviews were also excluded while for cohort studies, data were extracted from the baseline observation only.

\section{Data extraction}

All searched articles were imported into the EndNote X9 version software and then the duplicated files were removed. Based on the predetermined inclusion criteria, two independent review authors (MAFAR and MBM) determined qualified studies based on titles and abstract and from selected articles; the relevant information was extracted in the Microsoft Excel Spreadsheet for analysis. The date extraction sheet included the name of the first author, year of publication, region (state), geographical 
location (Peninsular or Borneo), study design, study group (subjects), sample size, sampling technique, period of study, diagnostic method (microscopy and/or PCR) and species-specific total positive finding.

\section{Statistical analysis}

Microscopy and/or PCR parasite prevalence were calculated for each study, once for all Plasmodium species single infection and mixed infections. Summary descriptive statistics using frequency and percentage for malaria cases were tabulated to obtain a clear understanding of the population studied. Incidence rate (reported per 100,000 population) was calculated based on the number of population in Malaysia for the respective year and region (i.e. sampling area) based on census from the Department of Statistics [31]. Sensitivity and specificity analysis for microscopy and PCR were calculated using microscopy as the reference technique and visually summarized in a box plot for easy-to-read visualization of the test accuracy variance between studies. All analyses were done using STATA SE version 15.1 (Stata Corp, TX, USA).

\section{Results}

\section{Data and study characteristics}

The literature search generated 466 results in PubMed, 354 in Scopus, 271 in Web of Science (Clarivate Analytic) and 909 in Elsevier (Science Direct) databases (Fig. 1).
After removing duplicates, 1202 articles were left for screening. Following screening of titles and abstracts, 295 studies were retained for more detailed evaluation. The most common reason for exclusion was the unavailability of data for analysis. Other reasons for exclusion including experimental studies, cohort studies, and reviews. As a result, 46 articles were selected in the study for full data extraction [5, 7-9, 23-25, 27, 28, 32-68].

\section{Description of included studies}

Of the 46 included studies, six studies (13\%) were published from 1988 to 1999 , followed by 11 studies (24\%) from 2000 to 2010 and 29 studies (63\%) from 2011 to June 2019 (Table 1). The majority of studies were conducted in Malaysia Borneo (31/46; 67.4\%), followed by Peninsular Malaysia (13/46; 28.3\%) and in both areas (2/46; 4.3\%). In term of sampling strategy, 33 studies derived from hospital data, 12 studies from population data and only one study from the combination of both hospital and population data.

In term of malaria diagnosis method, 28 studies utilized both microscopy and PCR, but in 18 of them, the samples tested for PCR were chosen from the microscopy positive cases for malaria species confirmation. Of those 18 studies tested for PCR, ten studies [7-9, 36-38, 41, 54, 56, 60] used all the microscopy positive cases, six studies [5, 33, $47,49,51,52]$ used more than $70 \%$ of the cases, one study [48] used $2.5 \%$ randomly selected cases, and one study

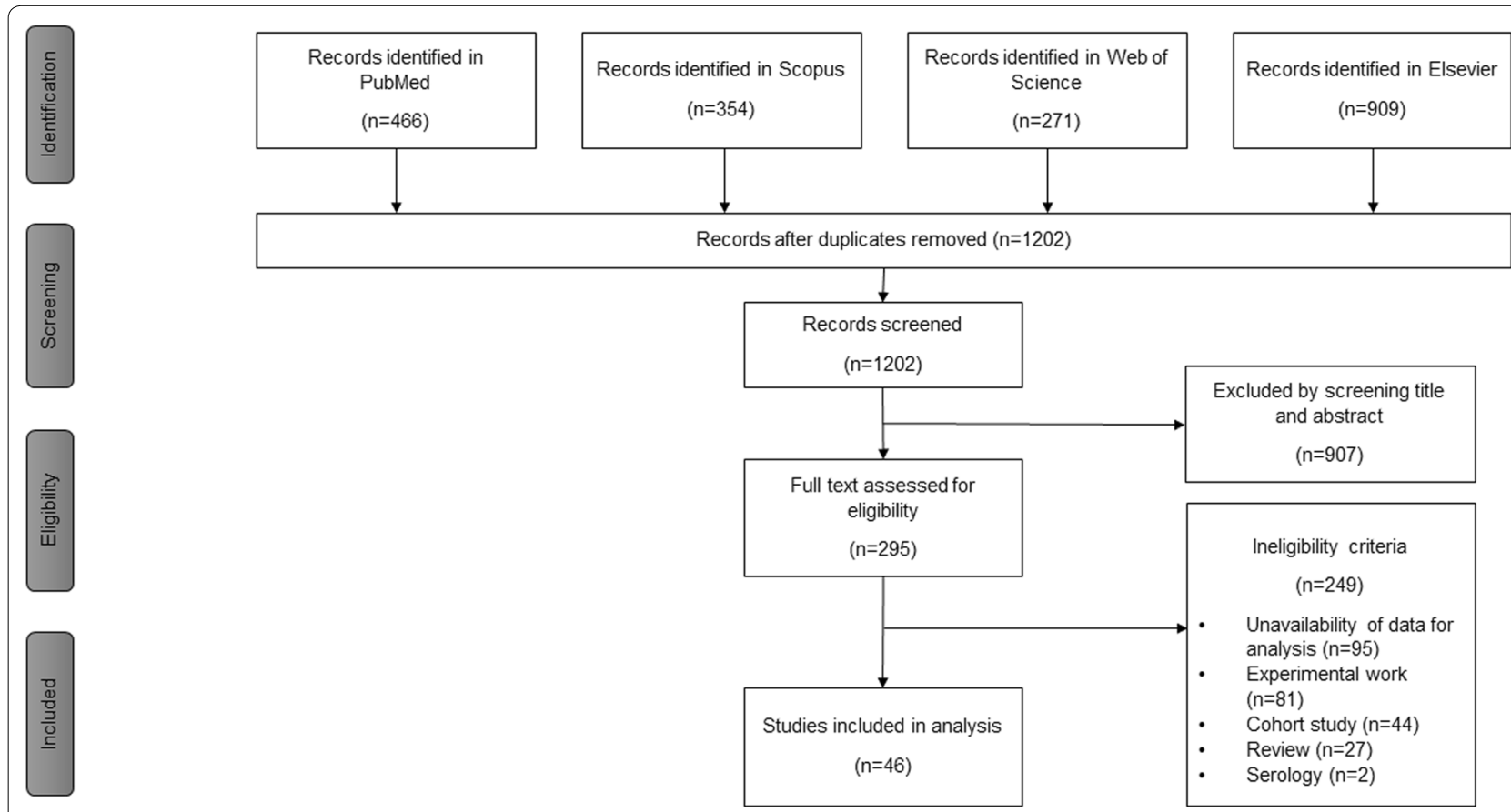

Fig. 1 Flowchart of selected articles for the systematic review according to the PRISM statement 


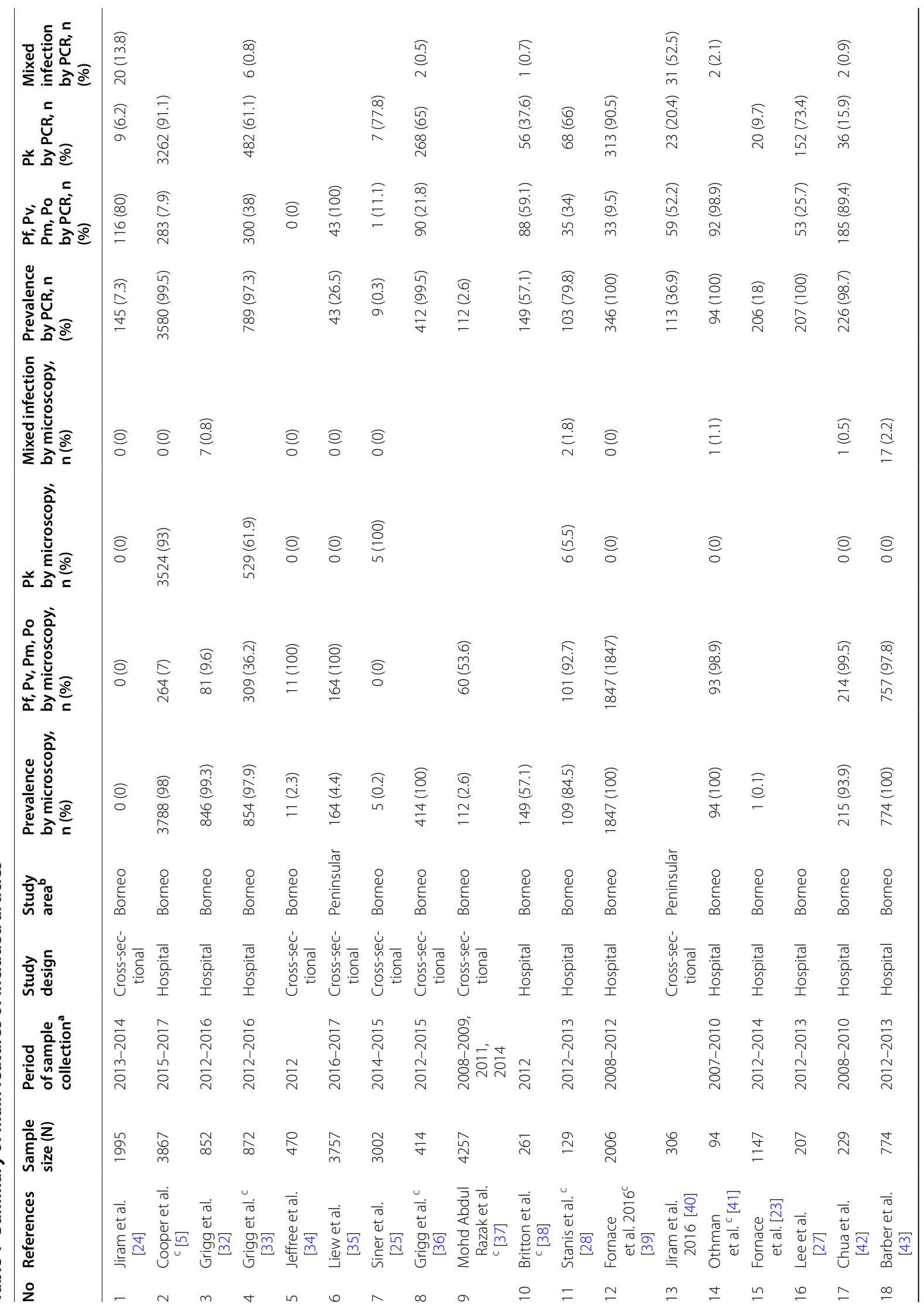




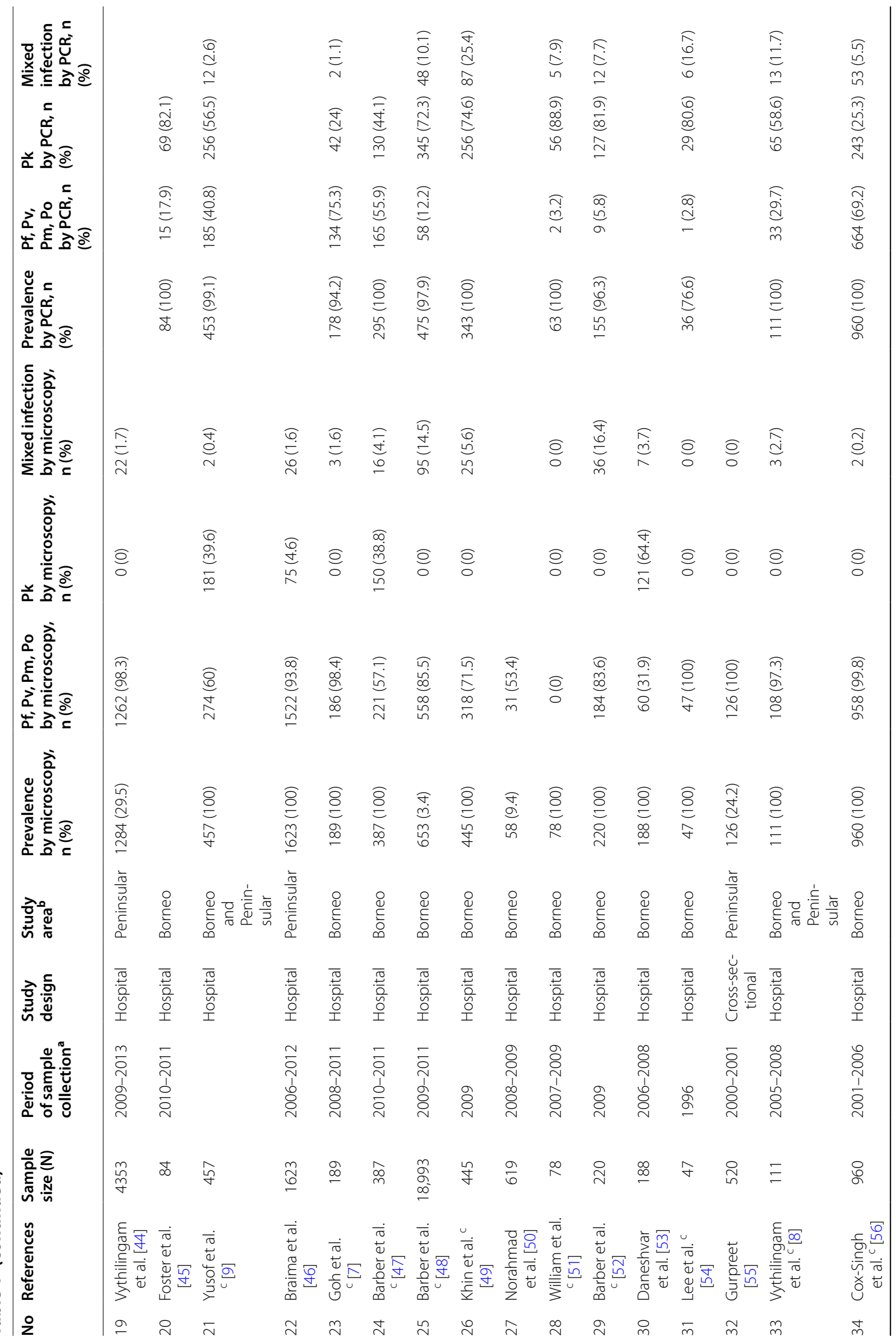




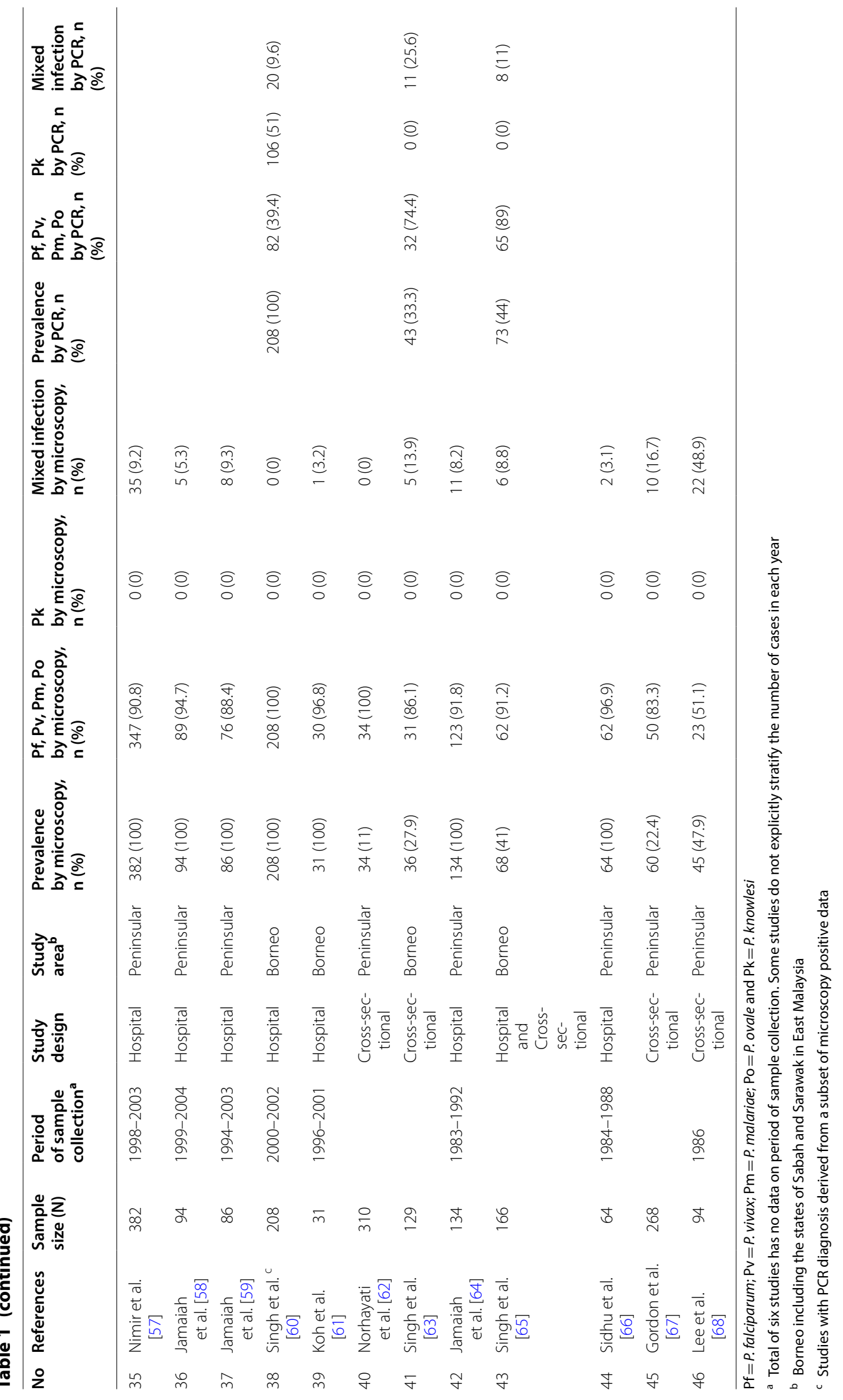


[39] used 19\% of microscopy positive cases for either $P$. malariae or P. knowlesi. Furthermore, of the 28 studies, ten studies [12, 24, 25, 28, 32, 35, 42, 53, 63, 65] conducted PCR on all samples regardless of the microscopy results in order to trace the sub-microscopic infections. In addition, 18 studies utilized only one method of detection for malaria: 15 [34, 43, 44, 46, 50, 55, 57-59, 61, 62, $64,66-68]$ by microscopy and three $[27,40,45]$ by PCR.

Overall, the median sample sizes were 308 cases (range 31-18,993) for microscopy and 261 (range 47-4257) for PCR. Most microscopy diagnosis used Giemsa-stained thick and thin smears $(\mathrm{n}=35)$, while the remaining studies $(n=8)$ used only thick smear. In studies using PCR methods $(n=31)$, the majority used conventional nested PCR $(n=22)$, followed by three studies used multiplex PCR and two studies used real-time PCR. Other studies $(\mathrm{n}=4)$ reported combination of different PCR methods; conventional/multiplex/real-time PCR, loop-mediated isothermal amplification (LAMP) assays [38], conventional/multiplex PCR assays [28], conventional/real-time PCR assays [12], and multiplex/real-time PCR assays [27].

\section{Parasite and incidence rates by year of sampling}

The parasite rate and average incidence rate by year of sampling are shown in Fig. 2. In total, seven cross-sectional [24, 25, 35, 36, 40, 63, 65] and 21 hospital-based studies [5, 7-9, 23, 27, 28, 33, 38, 39, 41, 42, 45, 47-49, 51, $52,54,56,60]$ with available PCR data for malaria species (1996 to 2017) were used to calculate trends in parasite rate and incidence rate, respectively. Generally, over the 22-year period, species predominance shifted from $P$. falciparum before 2000 to P. knowlesi from 2015 onward. Plasmodium knowlesi parasite rate rose drastically from 0.003 in 2014 to 0.399 in 2015, but declined to 0.187 and 0.131 in 2016 to 2017, respectively. Similar trend for incidence rate was also observed across the 22 years. Plasmodium falciparum incidence decreased from 0.836 per 100,000 in 2006 to 0.016 per 100,000 in 2017, and P. vivax from 1.679 per 100,000 in 2006 to 0.080 per 100,000 in 2017. In contrast, $P$. knowlesi incidence rate rose steadily throughout the years from 0.029 per 100,000 in 1996 to 5.909 per 100,000 in 2017.

\section{Sensitivity and specificity of detection methods}

The performance of microscopy and PCR in detecting Plasmodium spp. are shown in Fig. 3 . In total, 21 studies were included; 18 studies were undertaken in Malaysia Borneo [5, 7, 24, 25, 28, 33, 39, 41, 42, 47-49, 52, 54, $56,60,63,65]$, one study was in Peninsular Malaysia [35] and two studies were in both Peninsular Malaysia and Malaysia Borneo $[8,9]$. Overall, the summary estimate of sensitivity by microscopy was highest for P. knowlesi (35\%
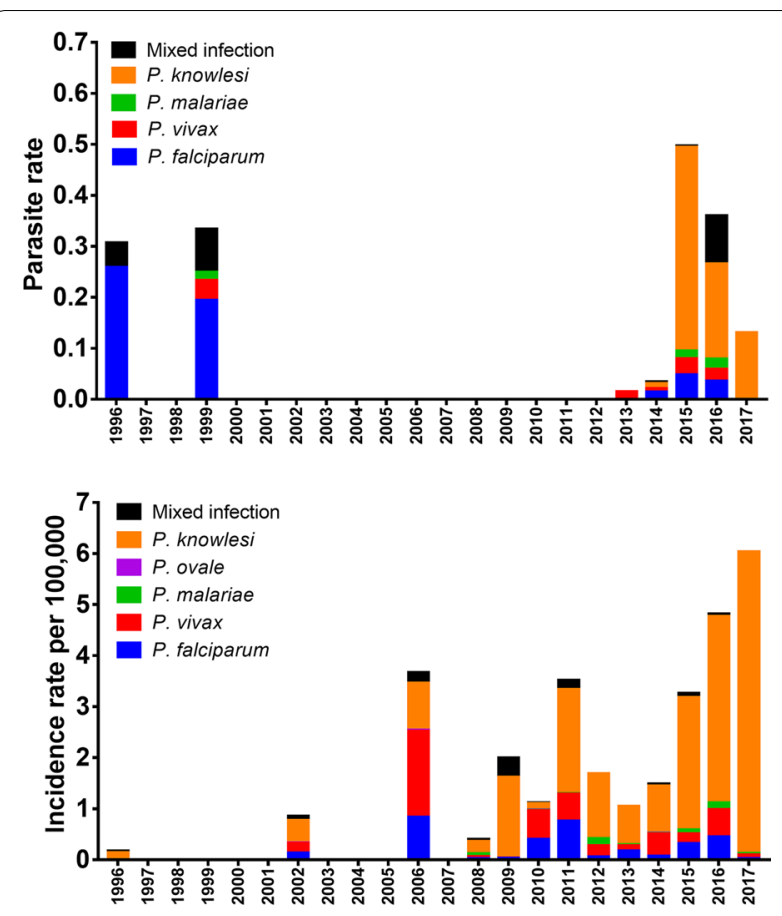

Fig. 2 Parasite rate by year of sampling collection based of available PCR data from cross-sectional studies $[24,25,35,36,40,63,65]$ between 1996 to 2017 (top). Incidence rate per 100,000 populations by year of sampling collection based on available PCR data from hospital-based studies $[5,7-9,23,27,28,33,38,39,41,42,45,47-49$, 51, 52, 54, 56, 60] between 1996 to 2017 (bottom)

[95\% CI 34-36]), followed by P. malariae (25\% [95\% CI 24-26]) and P. vivax (14\% [95\% CI 14-15]), and lowest for P. falciparum (11\% [95\% CI 10-11]). Nevertheless, the summary estimate of specificity by microscopy was similar in all species ranged $40-43 \%$.

Similar to microscopy, the summary estimate of sensitivity by PCR was highest for P. knowlesi with 56\% (95\% CI 55-57). Whereas, the summary estimate of sensitivity by PCR for $P$. vivax, $P$. falciparum and $P$. malariae were $14 \%$ (95\% CI 13-15), 11\% (95\% CI 10-11) and 1.6\% (95\% CI 1.4-1.9), respectively. On the other hand, the specificities of summary estimate for species-specific were less than $35 \%$ with $P$. knowlesi, $P$. vivax, $P$. falciparum and P. malariae were $34.5 \%$ (95\% CI 34-35), 34\% (95\% CI $33-35), 16.5 \%$ (95\% CI 16-17) and 2.3\% (95\% CI 2-3), respectively.

\section{Discussion}

Malaysia aims to eliminate malaria nationwide by 2020 . Although the country has successfully eliminated indigenous transmission of all human malaria species [3], the incidence of malaria caused by $P$. knowlesi continues to infect a large number of people in remote parts of Malaysia [5, 11, 69]. This is the first systematic 


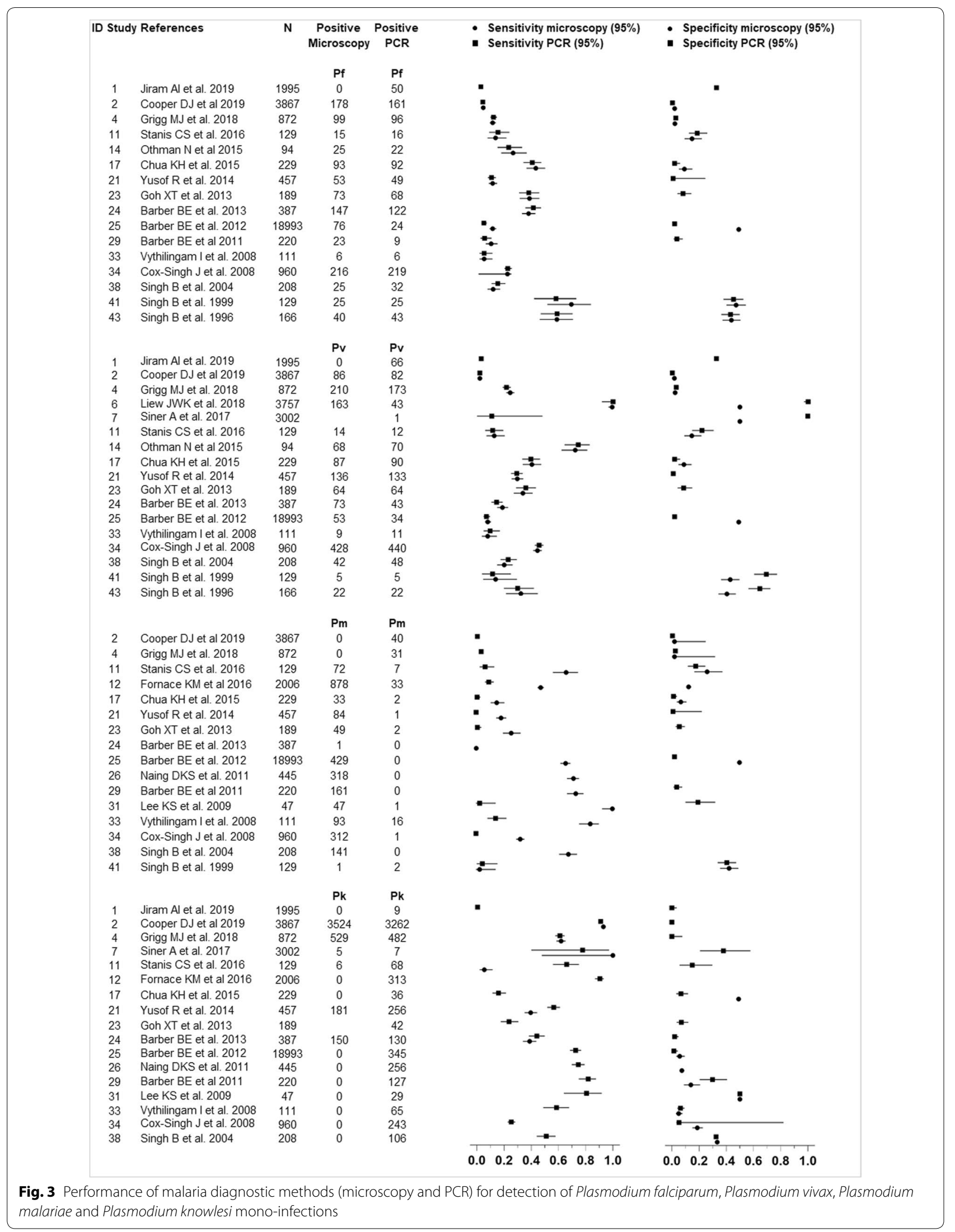


review to determine the pooled distribution of all malaria species and performance of major malaria diagnostic methods in Malaysia, based on English publications. The study has analysed 46 full-text publications reported since the 1980s in Malaysia.

In this study, malaria incidence caused by human malaria species indicates a decreasing trend from 2006 onwards. This finding is consistent with a recent study by Hussin et al. that showed the decreasing incidence of human malaria notified to the Ministry of Health, Malaysia between 2013 to 2017 [6]. This downward trend is a testament to the determination of the government and other parties to eliminate malaria in Malaysia. The Malaysia National Malaria Elimination Strategic Plan 2011-2020 has set the ultimate goal of stopping locally acquired malaria (except P. knowlesi) in the Peninsular region by 2015 and in the Malaysia Borneo region by $2020[4,17]$. The plan outlines seven key actions for achieving the elimination goal including strengthening the malaria surveillance system through an online system, stepping up control activities through indoor residual spraying (IRS) and insecticide-treated net (ITN), ensuring early case investigation, prompt treatment and outbreak management, and enhancing community awareness and knowledge of malaria. All these efforts have resulted in significant reduction in overall malaria incidence in general over the last decade.

Over the past years, malaria species-specific analysis showed that $P$. knowlesi was the most dominant species, particularly in Malaysia Borneo i.e. East Malaysia. Plasmodium knowlesi cases rose steadily year by year and the incidence rate was highest at 5.909 per 100,000 in 2017. Other than the wide utilization of molecular diagnosis in health facilities, it has been hypothesized that the rise of knowlesi malaria cases in the country was associated with ecological changes, particularly by deforestation $[11,36,70]$. The expansion of deforestation may have disturbed the habitat of mosquito vectors and simian hosts, as well as enhanced contact with the humans. In addition, the loss of habitat along with malaria control practices may have contributed to a change in vector behaviour or vector shift, as has been seen in the Kinabatangan area in Sabah where the previously dominant malaria vector Anopheles balabacensis seems to have been replaced by Anopheles donaldi [11, 71]. This is supported by the spatial distribution of reported cases in Sabah which are clustered in forested areas [39]. Besides that, it has been indicated that male adults are at a higher risk of knowlesi malaria infection than females due to the formers' occupational activity, which involves forestation or agricultural activities such as palm oil plantations that increase their exposure to the malaria vectors [72].
It was interesting to note that there was a dramatic reduction in both parasite and incidence rates of $P$. vivax and $P$. falciparum in Malaysia. Plasmodium vivax has been the main cause of human malaria in the country for the past 10 years and remains a health concern today [3]. In 2010, of the 5819 reported cases, approximately $60 \%$ were due to $P$. vivax [3]. Moreover, the potential for reactivation of dormant hypnozoites creates a number of difficulties for the elimination of malaria in the country [73]. The dramatic reduction of $P$. vivax observed in the present study also follows a steady increase in notification rate of $P$. malariae/P. knowlesi. In fact, over the past decade, a strong inverse correlation was observed between notification rates of $P$. malariae/P. knowlesi and $P$. vivax or $P$. falciparum $[11,72]$. This may be caused by misdiagnosis by microscopy of true $P$. falciparum or $P$. vivax infections as $P$. malariae/P. knowlesi [10, 74]. Moreover, it is less common in the most misdiagnosed of true $P$. knowlesi as $P$. falciparum or $P$. vivax [75]. The effect of this finding, as would be expected with increasing incidence of $P$. knowlesi and reducing incidence of $P$. vivax and P. falciparum.

Widely, the detection of malaria parasites by light microscopy of Giemsa-stained blood films continues to be the gold standard for malaria diagnosis [26]. It is however imperfect, especially when it comes to differentiation of malaria species. In this review, 15 studies relied solely on microscopy for Plasmodium detection and species differentiation. The use of microscopy as the sole diagnostic method likely leads to an underestimation of the malaria burden in a specific population [76], particularly in $P$. knowlesi and $P$. malariae infections that usually present at densities below the limit for microscopic detection [24]. This review also provided insight in the disparity between microscopy and PCR in diagnosing malaria cases. Most of the prevalence by microscopy were on human malaria (62.4\%), whereas the prevalence of zoonotic malaria (64.1\%) were typically reported by PCR. Microscopically, P. knowlesi infection is commonly misdiagnosed as $P$. malariae infection and other Plasmodium infections ( $P$. falciparum and $P$. vivax) due to their morphological similarities $[9,10]$. Although microscopic diagnosis of Plasmodium species is known to be problematic, this study demonstrates that the increase in notifications is likely to represent a real increase in the incidence of $P$. knowlesi. In this regard, PCR tests play an important role in order to confirm that the infection is due to knowlesi malaria.

A number of caveats should be considered in this study. First, the data used in the included studies were not uniform. The data gathered was solely based on published articles readily available on the internet and did not include data from the ministry of health. Thus, 
the findings of this study might not reflect the totality of malaria situation in Malaysia. In addition, most studies focused on the distribution of Plasmodium based on clinical samples and not in the population. This is possibly due to logistical difficulties and financial costs to carry the surveys, with most studies conducted in the Malaysia Borneo, where access to household is limited by geographic barriers. Second, our search strategy could have missed potentially eligible studies, because identification of Plasmodium infections were often not the primary target of many epidemiological studies in Malaysia. Third, the small sample size in some studies did not allow the evaluation of possible source of a high variation between studies.

\section{Conclusion}

This study outlined the epidemiological changes in Plasmodium species distribution in Malaysia. Malaria cases shifted from predominantly human malaria especially $P$. falciparum and P. vivax to $P$. knowlesi in the early 2000s. Plasmodium knowlesi is now responsible for the majority of malaria cases in the country. Therefore, malaria case notification and interventions in Malaysia should be strengthened and reinforced to achieving the final goal of malaria elimination in the country.

\section{Abbreviations \\ IRS: Indoor residual spraying; ITN: Insecticide-treated net; LAMP: Loop-medi- ated isothermal amplification; PCR: Polymerase chain reaction; RDT: Rapid diagnostic test; WHO: World Health Organization.}

\section{Acknowledgements}

We would like to acknowledge technical and management supports from Secretariat for Medical Research and Innovation (SPPI) and Centre for Research and Instrumentation (CRIM) from National University of Malaysia. We acknowledge Dr Chim W. Chan from Osaka City University, Japan who have given us additional insights for the manuscript.

\section{Authors' contributions}

All authors contributed sufficiently to this work. ZMI conceived the study. MAFAR and ZMI designed the study. MAFAR, MBM and ZMI analysed the data. MAFAR wrote the first draft of the manuscript. MAFAR and ZMI were responsible for critically revising the manuscript. All authors read and approved the final manuscript.

\section{Funding}

This work was supported by the Geran Pembiayaan Sepadan (FF-2019-124/1) from Faculty of Medicine, Universiti Kebangsan Malaysia (UKM). MBM was supported by the Hadiah Latihan Persekutuan (HLP) administrated by the Ministry of Health, Malaysia.

\section{Availability of data and materials}

The datasets used and/or analysed during the current study are available from the corresponding author on reasonable request.

\section{Ethics approval and consent to participate}

The ethical clearance was obtained from the Research and Ethics Committee of Universiti Kebangsaan Malaysia (Reference no: UKM PP1/111/8/ JEP-2019-148).

\section{Consent for publication}

Not applicable.

\section{Competing interests}

The authors declare that they have no competing interests.

Received: 13 May 2020 Accepted: 29 October 2020

Published online: 07 November 2020

\section{References}

1. WHO. World Malaria Report 2019. Geneva: World Health Organization; 2019a. p. 4-232.

2. WHO. World Malaria Report 2010. Geneva: World Health Organization; 2010. p. 238.

3. WHO. World Malaria Report 2018. Geneva: World Health Organization; 2018. p. 210.

4. WHO. The E-2020 Initiative of 21 Malaria Eliminating Countries 2019 Progress Report. Geneva: World Health Organization; 2019b. p. 16.

5. Cooper DJ, Rajahram GS, William T, Jelip J, Mohammad R, Benedict J, et al. Plasmodium knowlesi malaria in Sabah, Malaysia, 2015-2017: ongoing increase in incidence despite near-elimination of the human-only Plasmodium species. Clin Infect Dis. 2020;70:361-7.

6. Hussin N, Lim YA-L, Goh PP, William T, Jelip J, Mudin RN. Updates on malaria incidence and profile in Malaysia from, 2013 to 2017. Malar J. 2020;19:55.

7. Goh XT, Lim YA, Vythilingam I, Chew CH, Lee PC, Ngui R, et al. Increased detection of Plasmodium knowlesi in Sandakan division, Sabah as revealed by PlasmoNex. Malar J. 2013;12:264.

8. Vythilingam I, Noorazian YM, Huat TC, Jiram Al, Yusri YM, Azahari AH, et al. Plasmodium knowlesi in humans, macaques and mosquitoes in Peninsular Malaysia. Parasit Vectors. 2008;1:26.

9. Yusof R, Lau YL, Mahmud R, Fong MY, Jelip J, Ngian HU, et al. High proportion of knowlesi malaria in recent malaria cases in Malaysia. Malar J. 2014;13:168.

10. Singh B, Daneshvar C. Human infections and detection of Plasmodium knowlesi. Clin Microbiol Rev. 2013;26:165-84.

11. William T, Rahman HA, Jelip J, Ibrahim MY, Menon J, Grigg MJ, et al. Increasing incidence of Plasmodium knowlesi malaria following control of $P$. falciparum and P. vivax malaria in Sabah Malaysia. PLoS Negl Trop Dis. 2013;7:e2026.

12. Fornace K, Alexander N, Brock P, Grigg M, Murphy A, William T, et al. Association between landscape factors and spatial patterns of Plasmodium knowlesi infections in Sabah, Malaysia. Emerg Infect Dis. 2015;22:201-8.

13. Fornace K, Brock P, Grignard L, Herman L, Chua T, Daim S, et al. Environmental risk factors and exposure to the zoonotic malaria parasite Plasmodium knowlesi across northern Sabah, Malaysia: a population-based cross-sectional survey. Lancet Planet Health. 2019;3:e179-86.

14. Imai N, White MT, Ghani AC, Drakeley CJ. Transmission and control of Plasmodium knowlesi: a mathematical modelling study. PLoS Negl Trop Dis. 2014;8:e2978.

15. Shearer FM, Huang Z, Weiss DJ, Wiebe A, Gibson HS, Battle KE, et al. Estimating geographical variation in the risk of zoonotic Plasmodium knowlesi infection in countries eliminating malaria. PLoS Negl Trop Dis. 2016;10:e0004915.

16. Amir A, Cheong FW, de Silva JR, Liew JWK, Lau YL. Plasmodium knowlesi malaria: current research perspectives. Infect Drug Resist. 2018;11:1145-55.

17. Vector Borne Disease Control Sector. Malaria Situation in Malaysia. Disease Control Division, Malaysia Ministry of Health. 2014.

18. Amir A, Cheong F-W, De Silva JR, Lau Y-L. Diagnostic tools in childhood malaria. Parasit Vectors. 2018;11:53.

19. Berzosa P, de Lucio A, Romay-Barja M, Herrador Z, González V, García L, et al. Comparison of three diagnostic methods (microscopy, RDT, and $\mathrm{PCR}$ ) for the detection of malaria parasites in representative samples from Equatorial Guinea. Malar J. 2018;17:333.

20. Kagaya W, Gitaka J, Chan CW, Kongere J, Md Idris Z, Deng C, et al. Malaria resurgence after significant reduction by mass drug administration on Ngodhe Island. Kenya Sci Rep. 2019;9:19060. 
21. Ngasala B, Bushukatale S. Evaluation of malaria microscopy diagnostic performance at private health facilities in Tanzania. Malar J. 2019;18:375.

22. Kimura M, Teramoto I, Chan CW, Idris ZM, Kongere J, Kagaya W, et al. Improvement of malaria diagnostic system based on acridine orange staining. Malar J. 2018;17:72

23. Fornace KM, Nuin NA, Betson M, Grigg MJ, William T, Anstey NM, et al. Asymptomatic and submicroscopic carriage of Plasmodium knowlesi malaria in household and community members of clinical cases in Sabah. Malaysia J Infect Dis. 2016:213:784-7.

24. Jiram Al, Ooi CH, Rubio JM, Hisam S, Karnan G, Sukor NM, et al. Evidence of asymptomatic submicroscopic malaria in low transmission areas in Belaga district, Kapit division, Sarawak. Malaysia Malar J. 2019;18:156.

25. Siner A, Liew ST, Kadir KA, Mohamad DSA, Thomas FK, Zulkarnaen M, et al. Absence of Plasmodium inui and Plasmodium cynomolgi, but detection of Plasmodium knowlesi and Plasmodium vivax infections in asymptomatic humans in the Betong division of Sarawak, Malaysian Borneo. Malar J. 2017; 16:417.

26. Tangpukdee N, Duangdee C, Wilairatana P, Krudsood S. Malaria diagnosis: a brief review. Korean J Parasitol. 2009;47:93-102.

27. Lee PC, Chong ETJ, Anderios F, Al Lim Y, Chew CH, Chua KH. Molecular detection of human Plasmodium species in Sabah using PlasmoNex ${ }^{\mathrm{TM}}$ multiplex PCR and hydrolysis probes real-time PCR. Malar J. 2015;14:28.

28. Stanis CS, Song BK, Chua TH, Lau YL, Jelip J. Evaluation of new multiplex PCR primers for the identification of Plasmodium species found in Sabah, Malaysia. Turk J Med Sci. 2016;46:207-18.

29. Han TZ, Han KT, Aye KH, Hlaing T, Thant KZ, Vythilingam I. Comparison of microscopy and PCR for the detection of human Plasmodium species and Plasmodium knowlesi in southern Myanmar. Asian Pac J Trop Biomed. 2017:7:680-5

30. Moher D, Shamseer L, Clarke M, Ghersi D, Liberati A, Petticrew M, et al. Preferred reporting items for systematic review and meta-analysis protocols (PRISMA-P) 2015 statement. Syst Rev. 2015:4:1.

31. Department of Statistics, Malaysia. Population Estimates by States, 1996-2017, Malaysia.

32. Grigg MJ, William T, Piera KA, Rajahram GS, Jelip J, Aziz A, et al. Plasmodium falciparum artemisinin resistance monitoring in Sabah, Malaysia: in vivo therapeutic efficacy and kelch 13 molecular marker surveillance. Malar J. 2018;17:463.

33. Grigg MJ, William T, Barber BE, Rajahram GS, Menon J, Schimann E, et al. Age-related clinical spectrum of Plasmodium knowlesi malaria and predictors of severity. Clin Infect Dis. 2018;67:350-9.

34. Jeffree SM, Ahmed K, Safian N, Hassan R, Mihat O, Lukman KA, et al. Falciparum malaria outbreak in Sabah linked to an immigrant rubber tapper. Am J Trop Med Hyg. 2018;98:45-50.

35. Liew JWK, Mahpot RB, Dzul S, Abdul Razak HAB, Ahmad Shah Azizi NAB, Kamarudin MB, et al. Importance of proactive malaria sase surveillance and management in Malaysia. Am J Trop Med Hyg. 2018;98:1709-13.

36. Grigg MJ, Cox J, William T, Jelip J, Fornace KM, Brock PM, et al. Individuallevel factors associated with the risk of acquiring human Plasmodium knowlesi malaria in Malaysia: a case-control study. Lancet Planet Health. 2017:1:e97-104.

37. Mohd Abd Razak MR, Sastu UR, Norahmad NA, Abdul-Karim A, Muhammad A, Muniandy PK, et al. Genetic diversity of Plasmodium falciparum populations in malaria declining areas of Sabah, East Malaysia. PLoS ONE. 2016;11:e0152415.

38. Britton S, Cheng Q, Grigg MJ, Poole CB, Pasay C, William T, et al. Sensitive detection of Plasmodium vivax using a high-throughput, colourimetric loop mediated isothermal amplification (HtLAMP) platform: a potential novel tool for malaria elimination. PLoS Negl Trop Dis. 2016;10:e0004443.

39. Fornace KM, Abidin TR, Alexander N, Brock P, Grigg MJ, Murphy A, et al. Association between landscape factors and spatial patterns of Plasmodium knowlesi infections in Sabah. Malaysia Emerg Infect Dis. 2016;22:201-8.

40. Jiram Al, Hisam S, Reuben H, Husin S, Roslan A, Ismail W. Submicroscopic evidence of the simian malaria parasite, Plasmodium knowlesi, in an Orang Asli community. Southeast Asian J Trop Med Public Health. 2016:47:591-9.

41. Othman N, Basuni M, Muhi J, Miswan N, Noordin R. Soil-transmitted helminth infections among malaria patients determined by microscopy and real-time PCR methods at two district hospitals in Sarawak, Malaysia. Trop Biomed. 2015;32:710-6.
42. Chua KH, Lim SC, Ng CC, Lee PC, Lim YA, Lau TP, et al. Development of high resolution melting analysis for the diagnosis of human malaria. Sci Rep. 2015;5:15671.

43. Barber BE, Bird E, Wilkes CS, William T, Grigg MJ, Paramaswaran U, et al. Plasmodium knowlesi malaria during pregnancy. J Infect Dis. 2015;211:1104-10.

44. Vythilingam I, Lim YA, Venugopalan B, Ngui R, Leong CS, Wong ML, et al. Plasmodium knowlesi malaria an emerging public health problem in Hulu Selangor, Selangor, Malaysia (2009-2013): epidemiologic and entomologic analysis. Parasit Vectors. 2014;7:436.

45. Foster D, Cox-Singh J, Mohamad DS, Krishna S, Chin PP, Singh B. Evaluation of three rapid diagnostic tests for the detection of human infections with Plasmodium knowlesi. Malar J. 2014;13:60.

46. Braima KA, Sum JS, Ghazali AR, Muslimin M, Jeffery J, Lee WC, et al. Is there a risk of suburban transmission of malaria in Selangor, Malaysia? PLOS ONE. 2013:8:e77924.

47. Barber BE, William T, Grigg MJ, Menon J, Auburn S, Marfurt J, et al. A prospective comparative study of knowlesi, falciparum, and vivax malaria in Sabah, Malaysia: high proportion with severe disease from Plasmodium knowlesi and Plasmodium vivax but no mortality with early referral and artesunate therapy. Clin Infect Dis. 2013;56:383-97.

48. Barber BE, William T, Dhararaj P, Anderios F, Grigg MJ, Yeo TW, et al. Epidemiology of Plasmodium knowlesi malaria in north-east Sabah, Malaysia: family clusters and wide age distribution. Malar J. 2012;11:401.

49. Khin D, Naing DK, Anderios F, Lin Z. Geographic and Ethnic Distribution of P. knowlesi infection in Sabah, Malaysia. Int J Collab Res Intern Med Public Health. 2011;3:391-400.

50. Norahmad NA, Abdullah NR, Yaccob N, Jelip J, Dony JF, Ruslan KF, et al. High prevalence of pfcrt K76t mutants among Plasmodium falciparum isolates from Sabah, Malaysia. Southeast Asian J Trop Med Public Health. 2011;42:1322-6.

51. William T, Menon J, Rajahram G, Chan L, Ma G, Donaldson S, et al. Severe Plasmodium knowlesi malaria in a tertiary care hospital, Sabah. Malaysia Emerg Infect Dis. 2011;17:1248-55.

52. Barber BE, William T, Jikal M, Jilip J, Dhararaj P, Menon J, et al. Plasmodium knowlesi malaria in children. Emerg Infect Dis. 2011;17:814-20.

53. Daneshvar C, Davis TM, Cox-Singh J, Rafa'ee MZ, Zakaria SK, Divis PC, et al. Clinical and laboratory features of human Plasmodium knowlesi infection. Clin Infect Dis. 2009;49:852-60.

54. Lee KS, Cox-Singh J, Brooke G, Matusop A, Singh B. Plasmodium knowlesi from archival blood films: further evidence that human infections are widely distributed and not newly emergent in Malaysian Borneo. Int J Parasitol. 2009;39:1125-8.

55. Gurpreet K. Malaria endemicity in an Orang Asli community in Pahang. Malaysia Trop Biomed. 2009;26:57-66.

56. Cox-Singh J, Davis TM, Lee KS, Shamsul SS, Matusop A, Ratnam S, et al. Plasmodium knowlesi malaria in humans is widely distributed and potentially life threatening. Clin Infect Dis. 2008;46:165-71.

57. Nimir AR, Isa NH, Eugene CB, Ghauth IM, Salleh FM, Rahman RA. Severity of malaria cases reported in urban and rural hospitals in Malaysia. Southeast Asian J Trop Med Public Health. 2006;37:831-7.

58. Jamaiah I, Rohela M, Nissapatorn V, Mohamad Azlan H, Nor Adli AR, Shahrul Rizan I, et al. A retrospective prevalence study of malaria in an aborigine hospital in Gombak, Selangor, Malaysia. Southeast Asian J Trop Med Public Health. 2006;37:1-4.

59. Jamaiah I, Rohela M, Nissapatorn V, Khoo BL, Khoo PS, Radhiyah M, et al. Malaria: a 10-year (1994-2003) retrospective study at University Malaya Medical Center (UMMC), Kuala Lumpur, Malaysia. Southeast Asian J Trop Med Public Health. 2005;36:60-3.

60. Singh B, Kim Sung L, Matusop A, Radhakrishnan A, Shamsul SS, Cox-Singh $J$, et al. A large focus of naturally acquired Plasmodium knowlesi infections in human beings. Lancet. 2004;363:1017-24.

61. Koh $\mathrm{KH}, \mathrm{Chew} \mathrm{PH}$, Kiyu A. A retrospective study of malaria infections in an intensive care unit of a general hospital in Malaysia. Singapore Med J. 2004; 45:28-36

62. Norhayati M, Rohani AK, Hayati MI, Halimah AS, Sharom MY, Abidin AH, et al. Clinical features of malaria in Orang Asli population in Pos Piah. Malaysia Med J Malaysia. 2001;56:271-4.

63. Singh B, Bobogare A, Cox-Singh J, Snounou G, Abdullah MS, Rahman HA. A genus- and species-specific nested polymerase chain reaction 
malaria detection assay for epidemiologic studies. Am J Trop Med Hyg. 1999;60:687-92.

64. Jamaiah I, Anuar AK, Najib NA, Zurainee MN. Imported malaria: a retrospective study in University Hospital, Kuala Lumpur, a ten-year experience. Med J Malaysia. 1998;53:6-9.

65. Singh B, Cox-Singh J, Miller AO, Abdullah MS, Snounou G, Rahman HA. Detection of malaria in Malaysia by nested polymerase chain reaction amplification of dried blood spots on filter papers. Trans R Soc Trop Med Hyg. 1996;90:519-21.

66. Sidhu PS, Ng SC. A retrospective study on malaria cases admitted to the University Hospital, Kuala Lumpur, 1984-1988. Med J Malaysia. 1991:46:177-82.

67. Gordon DM, Davis DR, Lee M, Lambros C, Harrison BA, Samuel R, et al. Significance of circumsporozoite-specific antibody in the natural transmission of Plasmodium falciparum, Plasmodium vivax, and Plasmodium malariae in an aboriginal (Orang Asli) population of central peninsula Malaysia. Am J Trop Med Hyg. 1991;45:49-56.

68. Lee M, Davis DR, Ballou WR, Folena-Wasserman G, Lewis GE. Interaction of Malaysian sera with Plasmodium vivax sporozoite antigen. Am J Trop Med Hyg. 1988;39:535-9.

69. Ooi CH, Bujang MA, Tg Abu Bakar SidikTMI, Ngui R, Lim YA. Over two decades of Plasmodium knowlesi infections in Sarawak: trend and forecast. Acta Trop. 2017;176:83-90.

70. Ramdzan A, Ismail A, Zanib ZM. Prevalence of malaria and its risk factors in Sabah, Malaysia. Int J Infect Dis. 2020;91:68-72.
71. Vythilingam I, Chan ST, Shanmugratnam C, Tanrang H, Chooi KH. The impact of development and malaria control activities on its vectors in the Kinabatangan area of Sabah. East Malaysia Acta Trop. 2005;96:24-30.

72. William T, Jelip J, Menon J, Anderios F, Mohammad R, Awang Mohammad TA, et al. Changing epidemiology of malaria in Sabah, Malaysia: increasing incidence of Plasmodium knowlesi. Malar J. 2014;13:390.

73. Mat Ariffin N, Islahudin F, Kumolosasi E, Makmor-Bakry M. A clinical tool to predict Plasmodium vivax recurrence in Malaysia. BMC Infect Dis. 2017; 17:759.

74. Rajahram GS, Barber BE, William T, Grigg MJ, Menon J, Yeo TW, et al. Falling Plasmodium knowlesi malaria death rate among adults despite rising incidence, Sabah, Malaysia, 2010-2014. Emerg Infect Dis. 2016;22:41-8.

75. Jeremiah S, Janagond AB, Parija SC. Challenges in diagnosis of Plasmodium knowlesi infections. Trop Parasitol. 2014:4:25-30.

76. Idris ZM, Chan CW, Kongere J, Gitaka J, Logedi J, Omar A, et al. High and heterogeneous prevalence of asymptomatic and sub-microscopic malaria infections on islands in Lake Victoria. Kenya Sci Rep. 2016;6:36958.

\section{Publisher's Note}

Springer Nature remains neutral with regard to jurisdictional claims in published maps and institutional affiliations.
Ready to submit your research? Choose BMC and benefit from:

- fast, convenient online submission

- thorough peer review by experienced researchers in your field

- rapid publication on acceptance

- support for research data, including large and complex data types

- gold Open Access which fosters wider collaboration and increased citations

- maximum visibility for your research: over $100 \mathrm{M}$ website views per year

At BMC, research is always in progress.

Learn more biomedcentral.com/submissions 